\title{
Coupling X-ray microtomography and macroscopic soil measurements: a method to enhance near-saturation functions?
}

\author{
E. Beckers ${ }^{1}$, E. Plougonven ${ }^{2,}$, N. Gigot ${ }^{1}$, A. Léonard ${ }^{2}$, C. Roisin ${ }^{3}$, Y. Brostaux ${ }^{4}$, and A. Degré ${ }^{1}$ \\ ${ }^{1}$ Univ. Liège, GxABT, Soil-Water Systems, 2 Passage des Déportés, 5030 Gembloux, Belgium \\ ${ }^{2}$ Univ. Liège, Department of Applied Chemistry, Laboratory of Chemical Engineering, Sart-Tilman, 4000 Liège, Belgium \\ ${ }^{3}$ Walloon Agricultural Research Centre of Gembloux (CRA-W), Department of Agriculture and Natural Environment, \\ Soil Fertility and Water Protection Unit, 4 Rue du Bordia, 5030 Gembloux, Belgium \\ ${ }^{4}$ Univ. Liège, GxABT, Applied Statistics, Computer Science and Mathematics Unit, 2 Passage des Déportés, \\ 5030 Gembloux, Belgium \\ *now at: ICMCB-CNRS/Group 4, 87 Avenue du Docteur Albert Schweitzer, 33608 Pessac, France
}

Correspondence to: E. Beckers (eleonore.beckers@ulg.ac.be)

Received: 27 February 2013 - Published in Hydrol. Earth Syst. Sci. Discuss.: 15 April 2013

Revised: 31 March 2014 - Accepted: 6 April 2014 - Published: 20 May 2014

\begin{abstract}
Agricultural management practices influence soil structure, but the characterization of these modifications and consequences are still not completely understood. In this study, we combine X-ray microtomography with retention and hydraulic conductivity measurements in the context of tillage simplification. First, this association is used to validate microtomography information with a quick scan method. Secondly, X-ray microtomography is used to increase our knowledge of soil structural differences. Notably, we show a good match for retention and conductivity functions between macroscopic measurements and microtomographic information. Microtomography refines the shape of the retention function, highlighting the presence of a secondary pore system in our soils. Analysis of structural parameters for these pores appears to be of interest and offers additional clues for soil structure differentiation, through - among others - connectivity and tortuosity parameters. These elements make microtomography a highly competitive instrument for routine soil characterization.
\end{abstract}

\section{Introduction}

Tillage simplification has become a popular practice in recent years, mainly in order to save energy and reduce erosion. Agricultural management practices influence soil structure, as stated in numerous papers which have addressed the effects of tillage intensity on soil (see Strudley et al., 2008 for a review on the subject). However, changes in soil hydrodynamic behaviour are not fully understood and are still studied (Schlüter et al., 2011; Eden et al., 2012; Holthusen et al., 2012 for example). Furthermore, researchers have drawn divergent conclusions over the impact of tillage practices on soil hydraulic properties (e.g. Green et al., 2003; Cousin et al., 2004; Bhattacharyya et al., 2006; Strudley et al., 2008), though for most of them, pore size distribution, connectivity and orientation are involved. These changes in porosity suggest that the related hydrodynamic properties will be affected, as well as water fluxes and their partition. But the characterization of these modifications and consequences remains a challenge.

Plot-scale measurements, on the one hand, allow characterization of the global behaviour, but do not provide mechanistic explanations of structural modifications. The divergence in the literature with regard to agricultural management impacts shows the inability of these measurements to comprehend them completely. On the other hand, microscale characterization, involving small soil samples (with accuracy to within a micron or less), can offer helpful insight on the pore structure, but might not be representative at the plot scale. Notably, X-ray tomography has been recently used in order to characterize changes in soil pore distribution in different contexts, and attempts to link microtomography information to hydrodynamic measurement. 
Already in 1997 Olsen and Borresen (1997) were studying pore characteristics depending on tillage intensity with computed tomography. However, with a pixel size of $0.5 \mathrm{~mm}$, they only concluded about the macroporosity distribution in the soil profile. Since then, soil porosity has been analysed many times using X-ray tomography (see Taina et al., 2008 for the state of the art), but research on the link between macroscopic measurements and microscopic investigation of the soil structure remains scarce. Wiermann et al. (2000) showed the interest of this technique by combining water retention, hydraulic conductivity and tomography analyses to compare soil reaction to precompression stress depending on management practices. Kumar et al. (2010) and Kim et al. (2010) tried to explain saturated hydraulic conductivity ( $\left.K_{\text {sat }}\right)$ differences by pore parameter measurements with computed tomography, and found that most of these parameters were correlated with $K_{\text {sat }}$. Rachman et al. (2005) and Quinton et al. (2009) studied macroporosity through X-ray tomography and water retention curves; they concluded that these methods lead to comparable results for porosity distributions. Dal Ferro et al. (2012), for their part, analysed soil porosity with mercury intrusion porosimetry and X-ray microtomography. They highlighted the fact that microtomography does not take into account all the microporosity, and therefore advised combining microtomography analyses with other techniques. Cousin et al. (2004) conducted a two-scale study in order to determine more parameters: qualitative observation of macroporosity through stained infiltration combined with laboratory hydraulic conductivity measurements and tomographic analyses. They reported a better plot-scale conductivity in no tillage due to the presence of earthworm tunnels. The scarcity of these tunnels leads to the need for macroscopic measurements while tomographic observations allow a quantitative characterization of the bulk soil pore network. However, the achieved resolution in their study (i.e. $0.4 \mathrm{~mm}$ pixel size) was not sufficient to confirm a link between the pore network and in situ hydraulic conductivity measurements. Finally, Bayer et al. (2004) tested the ability of microtomography to provide water retention curves through a dynamic setup. Their results were in good agreement with a classical multistep outflow experiment. It can be seen that microtomography has become an interesting tool for the study of soil pore networks, as it provides a 3-D visualization of the internal soil structure. Furthermore, microtomography offers the possibility to extract pore size distribution as well as structural parameters. Among them, pore connectivity, which influences hydrodynamics (Vogel and Roth, 1998), or specific surface (surface area/volume) (Gerke, 2012) can be estimated.

In this study, we test X-ray microtomography as a tool to help differentiate soil structure modification due to tillage intensity through multiscale measurements. This association could help highlight the most influential microstructural factors affecting macroscopic transport phenomena. Water retention and hydraulic conductivity measurements on the one hand, and X-ray microtomography ( $34 \mu \mathrm{m}$ pixel size) on the other hand, compose the experimentation campaign. Water retention and hydraulic conductivity measurements are used frequently in other studies to show the effect of tillage intensity on soils. Furthermore, they are linked together and can lead to different estimations of the same parameter. This choice enables us to validate microtomographic results and to use the latter as an explanatory element of the fundamental processes highlighted by macroscopic measurements. However, the consistency of the results depends on the quality of the tomographic reconstructions. Quality is, among other factors, correlated with acquisition time. As a result microtomography as a hydraulic measurement technique is often considered as time-consuming in comparison with other techniques. In our study, we show that relatively fast scans supply not only a good match with other measurements, but also improve retention and hydraulic curves modelling near saturation $(|h|<10$ mbar). Microstructural parameters calculated on the pore network appear to be of interest to characterize tillage differences. These elements make microtomography a competitive instrument for routine soil characterization.

\section{Material and methods}

In this paper, we test X-ray microtomography as a tool to help quantification of soil structure modification due to tillage intensity. To do this, we couple what we call "micro" and "macroscopic" measurements: "microscopic" measurements refer to measurements that supply characterization at the pore scale; in opposition, the expression "macroscopic measurements" gathers all the measurements that are not at the pore scale. Establishment of 3-D soil strength profiles serves as a first visualization of soil structural differences and as a basis to organize sampling and measurement campaigns. Microscopic investigations consist in measuring 3-D morphological parameters using X-ray microtomography $(\mu \mathrm{CT})$. Macroscopic investigations include retention data with the pressure plate method (Richards' apparatus), saturated and unsaturated soil hydraulic conductivity.

Retention and hydraulic curves are derived from both microscopic and macroscopic investigations, and compared. Morphological parameters obtained with X-ray microtomography are analysed with principal component analysis.

Variability at the plot scale was assessed through the use of at least seven repetitions for each soil measurement, which seems sufficient to obtain a good approximation of the global behaviour for each object. For reasons of space, statistical analyses concerning soils comparison are not presented here. It has to be noted, however, that when the term significant is used in the following paragraphs it refers to a $p$ value of maximum 0.05 . 


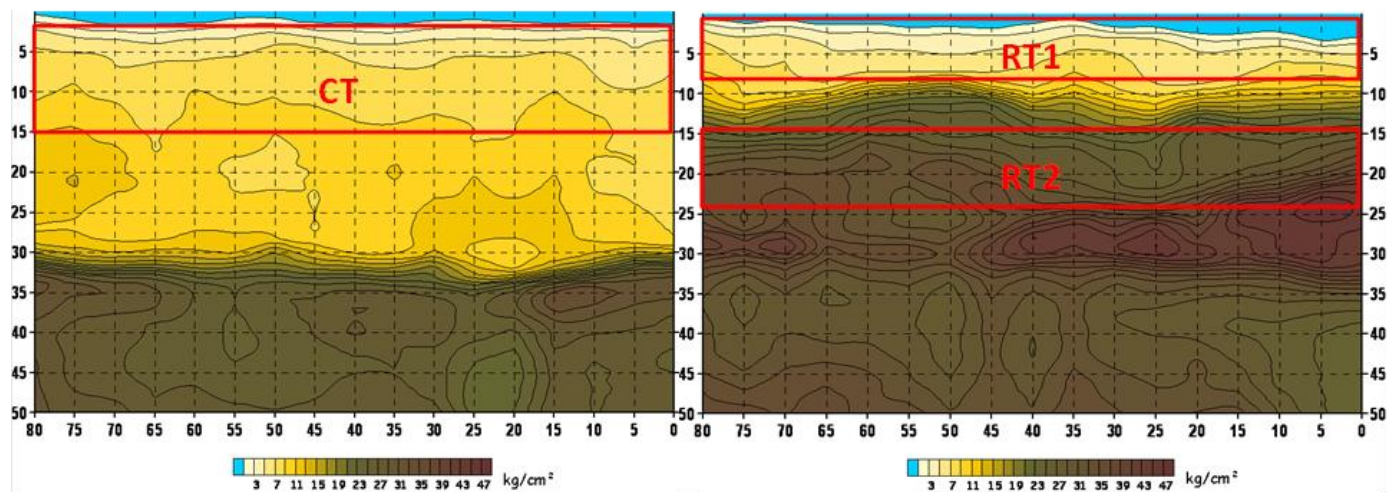

Figure 1. 3-D soil strength profiles. Left panel: CT profile; right panel: RT profile.

\subsection{Location}

Our field experiment takes place in Gentinnes (Walloon Brabant, Belgium), on a field organized in a Latin square scheme. Since 2004, plots (one plot is used here) have been cultivated in conventional tillage (CT), deep loosening (not studied here), or in reduced tillage (RT). The latter consists in sowing after stubble ploughing of about $10 \mathrm{~cm}$. The crop rotation is sugar beet, winter wheat, flax. The soil is mainly composed of silt loam and can be classified as a Luvisol.

A fully automated penetrometer mounted on a small vehicle was used to illustrate soil resistance to penetration (see Fig. 1). The surface area of $160 \times 80 \mathrm{~cm}^{2}$ and its position were chosen considering the characteristics of the agricultural management practices (more information can be found in Roisin, 2007). On this figure, we can observe two different soil horizons for both practices. In the CT profile, the second horizon appears at approximately $30 \mathrm{~cm}$. The upper layer, from 0 to $30 \mathrm{~cm}$, is quite homogeneous with a slight gradient along the depth. In the RT profile, the second horizon appears between 10 and $15 \mathrm{~cm}$. The old plough pan is still observed at $30 \mathrm{~cm}$ depth. Because of these observations and the variation in tillage depth between management practices $(10 \mathrm{~cm}$ for RT vs. $25 \mathrm{~cm}$ for CT), two horizons are investigated for RT - RT1 between 0 and $10 \mathrm{~cm}$ and RT2 between 12 and $25 \mathrm{~cm}$ (see Fig. 1) - while CT is considered as homogeneous.

\subsection{Measurement techniques}

\subsubsection{X-ray microtomography}

X-ray microtomography consists of performing series of Xray radiograms at different angles, producing enough information to algorithmically reconstruct a 3-D X-ray attenuation map of the sample. The transmitted X-ray intensity depends on the attenuation coefficient of each material located along the X-ray path, in a cumulative way. The attenuation coefficient is related to the material properties, i.e. its density and atomic number (Attix and Roesch, 1968) and to the energy of the incident beam.

\section{Sampling}

Soil sample dimensions have been chosen according to the tomograph characteristics. The cylindrical samples are $5 \mathrm{~cm}$ in height and $3 \mathrm{~cm}$ in diameter, allowing for a good compromise between resolution and time acquisition. Eight soil samples $\left(35 \mathrm{~cm}^{3}\right)$ are removed from each horizon (CT, RT1 and RT2) and are exposed to a 15 bar pressure according to Richards' procedure (Richards, 1948; DIN ISO 11274, 2012). Samples are therefore around the wilting point and pores with a radius above $0.1 \mu \mathrm{m}$ are meant to be free of water. Samples were collected very carefully. However, they are prone to cracks close to the sample container. As a result, the radius of image investigation is reduced a little to eliminate these effects. Final radii are the same for all our samples. Figure 2 gives a 3-D representation of pores for each horizon.

\section{X-ray microtomograph}

Samples are scanned using a Skyscan-1172 high-resolution desktop micro-CT system (Skyscan, Kontich, Belgium). The cone beam source operates at $100 \mathrm{kV}$, and an aluminium filter is used. The detector configuration (16 bit X-ray camera with $2 \times 2$ binning, creating $2048 \times 1024$ pixel radiograms) and the distances between source-object-camera are adjusted to produce images with a pixel size of $34 \mu \mathrm{m}$. The rotation step is $0.4^{\circ}$ over $180^{\circ}$. We perform here what can be called a fast scan, in a total of about $2 \mathrm{~h}$ per sample. Since the objects are larger than the field of view of the detector, several sets of radiograms are taken and stitched together. The final projections are actually mosaics of 3 by 2 radiograms, meaning that one set of radiograms is acquired in about $20 \mathrm{~min}$, which is relatively fast. In fact, the aim of this procedure is to have a good compromise between the acquisition quality, time and number of samples. 

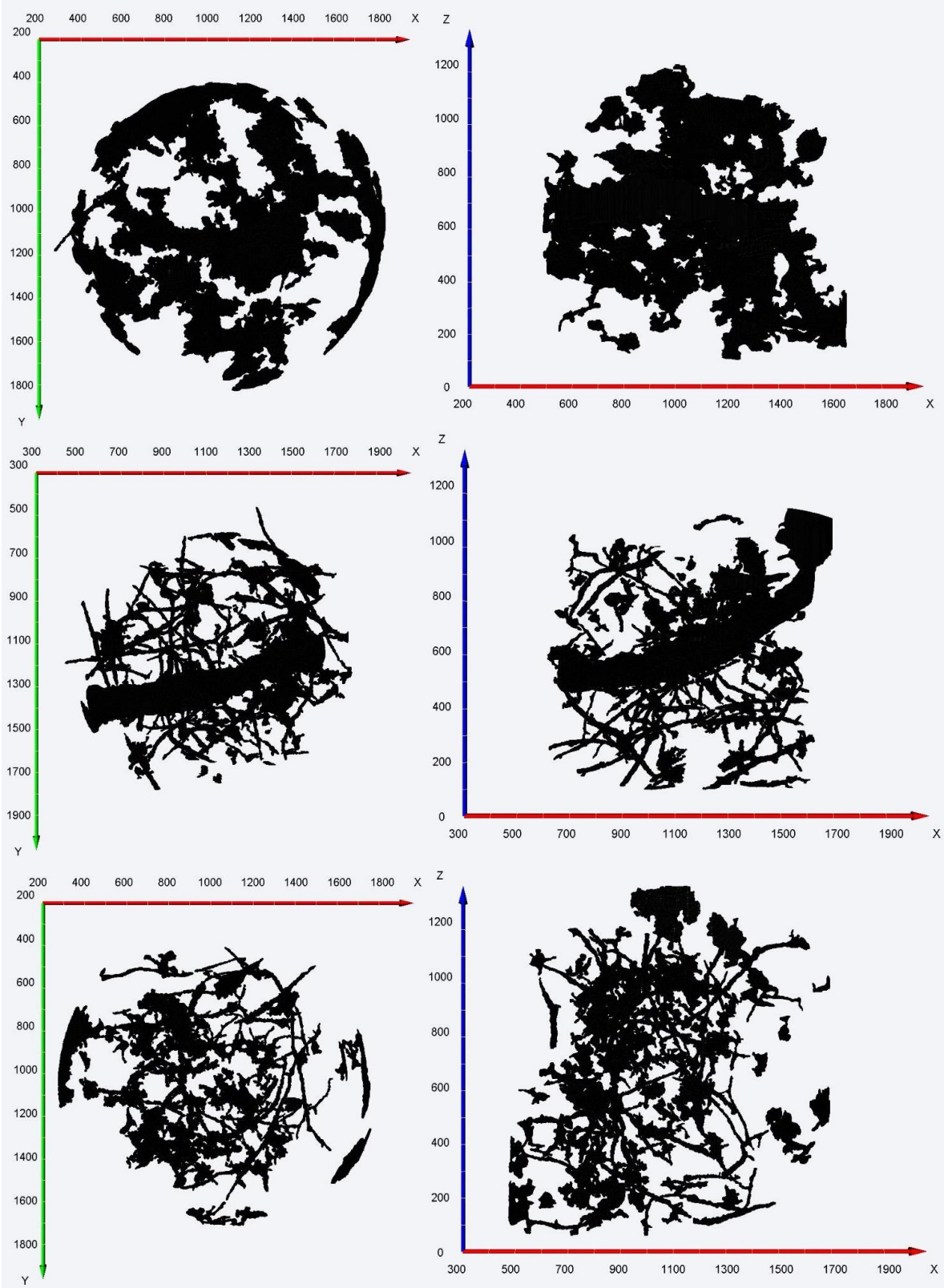

Figure 2. 3-D visualization of pores for each soil object for half samples (i.e. $2.5 \mathrm{~cm}$ height and $3 \mathrm{~cm}$ in diameter); CT, RT1, RT2, from top to bottom panels; XY view at the left panels; XZ view at the right panels.

\section{Image reconstruction}

Reconstruction is performed with the NRecon software ${ }^{\circledR}$ supplied with the Skyscan Micro-CT system. Ring artefact correction and rotation axis misalignment compensation is used. The resulting cross sections are then stacked and imported into Avizo ${ }^{\circledR}$ to be processed.

\section{Image processing}

In order to process our microtomograms, we use an algorithm developed by Plougonven (2009; Plougonven and Bernard, 2011) and integrated into the Avizo ${ }^{\circledR}$ software. This algorithm is organized in two steps, a pre-processing of the images (noise reduction thanks to a greyscale opening, followed by a Gaussian filtering) and a post-processing to decompose the porosity into individual pores, and calculate morphological parameters. Between these two steps, a threshold value needs to be chosen. 


\section{Segmentation}

The choice of the segmentation method is not so obvious. Numerous methods exist and these methods can be global (i.e. a same threshold value for the entire domain) as well as local (i.e. the value is adapted regarding local characteristics). Review papers or research articles comparing segmentation methods (for example Iassonov et al., 2009; Wang et al., 2011) show that there is no ideal segmentation method in the context of soil analyses. Following Iassonov et al. (2009), the method has to be chosen considering the context of the study, and factors to be taken into account are principally "the reliability and consistency of the method, as well as the computational efficiency and the automated character of it". Local vs. global methods show different advantages considering these factors. Local methods dedicated to soils are very promising (e.g. Schlüter et al., 2010; Hapca et al., 2013; Houston et al., 2013), but they are more demanding in terms of time and computational resource. In the present study, we decide to apply a single mean threshold value (based on the soil porosity). This procedure has been validated and shows results nearly as good as the local methods cited before (see Beckers et al., 2014 for more details). Furthermore, the studied objects are soils with structural differences only. Our approach is comparative and our choices' impact can be supposed equivalent for the different studied objects.

\section{Post-process}

Once the threshold value is chosen, the part of the algorithm calculating morphological parameters can be applied in Avizo ${ }^{\circledR}$. It provides local 3-D quantification based on pore space decomposition. The decomposition method is a watershed-based approach on the Euclidean distance transform of the porous phase, given specific pre-processing (Plougonven and Bernard, 2011), with the basins defined from both topological information (i.e. the intersection of branches in the skeleton) and geometrical information (postmerging of basins given certain geometric conditions, for more details see Plougonven, 2009). For each pore (following the definition of the current pore space decomposition), parameters are computed as illustrated in Fig. 3: volume (Vol), surface (determined from the number of voxel faces), barycentre, inertia tensor (defined as if the pore was an object with uniform mass, and on which the inertia matrix is computed), number of neighbouring pores $\left(N_{\mathrm{c}}\right)$, surface area of the connections $\left(\mathrm{Sf}_{\mathrm{c}}\right)$ and equivalent radius of the connections. Additionally, we compute the specific surface (SS) for each pore, and the pore deformation (Def), defined as the ratio between minimum and maximum components of the inertia tensor. Using this deformation, an elliptic cylinder was fitted to the pores in order to calculate a mean radius $(R)$. Finally, we calculate a variable related to specific connectivity (SC):

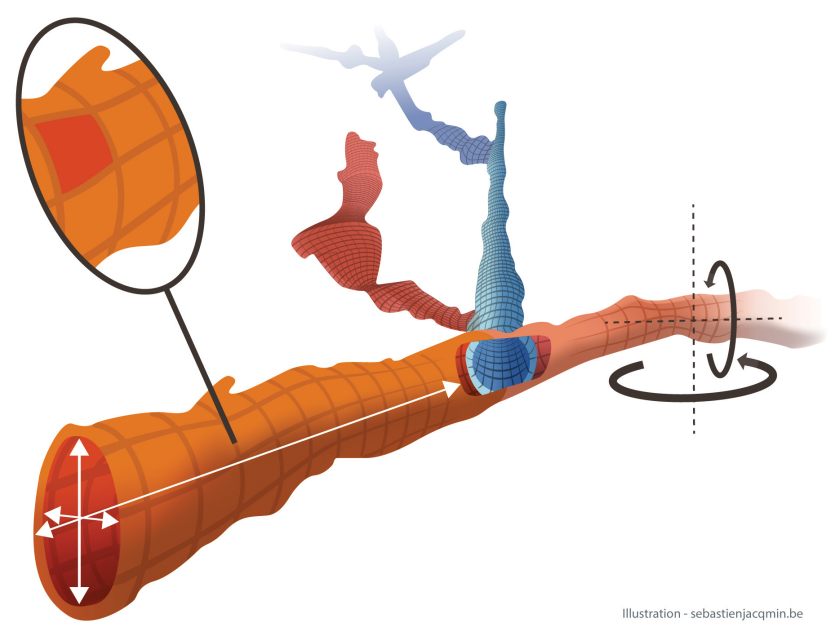

Figure 3. Representation of a theoretical pore network. The following morphological measurements are illustrated: on the left, dimensions of the pore as an elliptic cylinder (double white arrows); on the left, pore surface measurement determined from the number of voxel faces (see magnifying glass); in the middle, connection characterization (pore hole); on the right, inertia tensors measurements (black arrows).

$\mathrm{SC}=\frac{N_{\mathrm{c}} A_{\mathrm{c}}}{V_{\mathrm{p}}}$

where $N_{\mathrm{c}}$ is the number of connections, $A_{\mathrm{c}}$ the mean surface area of the connections $\left(\mathrm{L}^{2}\right)$ and $V_{\mathrm{p}}$ the pore volume $\left(\mathrm{L}^{3}\right)$.

\subsubsection{Water retention}

Retention points are obtained thanks to the Richards procedure on one hand (Richards, 1948; Dane and Hopmans, 2002 cited by Solone et al., 2012; DIN ISO 11274, 2012), and thanks to X-ray microtomography on the other hand.

With Richards' procedure, samples are saturated by upward moisturizing during $48 \mathrm{~h}$, exposed to increasing pressures between 10 mbar to $15 \mathrm{bar}(\mathrm{pF} 1$ to 4.2$)$, and weighed between each stage. Seven soil samples $\left(100 \mathrm{~cm}^{3}\right)$ are taken from each horizon (CT, RT1 and RT2).

Pore size distribution derived from tomographic results allows calculating retention data points between $\mathrm{pF} 1(10 \mathrm{mbar})$ and saturation. Samples are around the wilting point during scanning procedure (see Sect. 2.2.1).

Pore size distribution is obtained from microtomographic measurements using the following relationship (capillary theory, Jurin's law):

$r=\frac{2 \sigma \cos (\alpha)}{\rho g h}$

where $r$ is the pore radius (L), $h$ is the pressure head (L), $\sigma$ is the liquid surface tension $\left(\mathrm{M} \mathrm{T}^{-2}\right), \alpha$ is the contact angle between the liquid and the soil, $\rho$ is the liquid density $\left(\mathrm{ML}^{-3}\right)$ and $g$ is the gravitational acceleration $\left(\mathrm{LT}^{-2}\right)$. The radius 
is determined with structural parameters measured thanks to X-ray microtomography (see Sect. 2.2.1, Post-process).

\subsubsection{Hydraulic conductivity}

\section{In situ measurements}

In situ infiltration measurements are performed by a $20 \mathrm{~cm}$ diameter tension-infiltrometer (TI) (Eijkelkamp Agrisearch Equipment). Eight repetitions are made for each management practice. For each location, three infiltration measurements for tensions of $-9,-6$ and -3 mbar are performed. Measurements are long enough to have at least $18 \mathrm{~min}$ of steady-state infiltration. We only use the unsaturated flows, saturated hydraulic conductivity being measured directly in the laboratory. Concerning measurements for RT1, this layer presents a shallow thickness (max $10 \mathrm{~cm}$, see Fig. 1). Moreover, to obtain the mandatory plane surface for TI measurements, a part of it had to be removed. As a result, these measurements are likely to be attributed to RT2.

\section{Laboratory measurements}

We use a permeameter (Laboratory-Permeameter, Eijkelkamp, Giesbeek, Netherlands) to measure saturated hydraulic conductivity on $100 \mathrm{~cm}^{3}$ soil samples. The basic principle is to create a pressure gradient between the sides of the sample and to measure the flow coming out. The constant head method is used (Klute, 1986 cited by Bayer et al., 2004). Considering the possible change in pore orientation, we measure this conductivity in the two main orientations: vertical conductivity vs. horizontal conductivity (parallel to the slope). Measurements are performed on eight samples for each object (CT, RT1 and RT2) and each orientation, and the mean value for $K_{\text {sat }}$ is calculated in each direction. In this paper we use the highest value between the mean horizontal and the mean vertical one, considering that the 3-D pore network characteristics are more correlated with this highest value.

\subsection{Measurements analysis}

\subsubsection{Retention and hydraulic functions}

Continuous functions can be adjusted on our retention data points coming from Richards' measurements and microtomography. Using $K_{\text {sat }}$ measured with the permeameter and parameters from these fitted retention data, $K(h)$ curves can be compared with TI measurements for each object. The agreement between these points serves as an indicator of the relevance of microtomography measurements.

However, numerous models exist. Since we study the nearsaturation behaviour, this part of the curve will be of great importance. According to Durner (1994), the largest differences in retention and hydraulic predictions are not caused by the choice of the single porosity model, but by taking into account - or not - supplementary pore systems. Indeed, Durner (1994) states that errors in hydraulic predictions can come from the fact that some pore distributions are bimodal (or multimodal) instead of unimodal, each mode being considered as one pore system. In such a context, one model of each type has been adjusted (using the LevenbergMarquardt algorithm, Levenberg, 1944; Marquardt, 1963): the unimodal from van Genuchten (1980) and the bimodal from Durner (1994). The associated hydraulic model is of Mualem (1976) for both cases.

The van Genuchten formulation is

$\theta(h)=\theta_{\mathrm{r}}+\frac{\theta_{\mathrm{s}}-\theta_{\mathrm{r}}}{\left[1+|\alpha h|^{n}\right]^{m}}$

with $\theta_{\mathrm{r}}$ the residual water content, $\theta_{\mathrm{S}}$ the saturated water content, $n$ a pore size distribution parameter, $\alpha$ the inverse of the bubbling pressure $\left(\mathrm{L}^{-1}\right)$ and $m$ a function of $n(m=1-1 / n)$. The associated hydraulic conductivity is expressed as follows (Mualem, 1976):

$K(h)=K_{\mathrm{s}} S_{\mathrm{e}}^{l}\left[1-\left(1-S_{\mathrm{e}}^{1 / m}\right)^{m}\right]^{2}$

with $K_{\mathrm{S}}$ the saturated hydraulic conductivity $\left(\mathrm{L} \mathrm{T}^{-1}\right), l$ a pore connectivity parameter, and $S_{\mathrm{e}}$ the effective saturation:

$S_{\mathrm{e}}=\frac{\theta-\theta_{\mathrm{r}}}{\theta_{\mathrm{s}}-\theta_{\mathrm{r}}}$.

With the dual porosity model (Durner, 1994) the effective saturation becomes

$S_{\mathrm{e}}=w_{1}\left[1+\left(\alpha_{1} h\right)^{n_{1}}\right]^{-m_{1}}+w_{2}\left[1+\left(\alpha_{2} h\right)^{n_{2}}\right]^{-m_{2}}$

with $w$ the weighing factor, and subscripts 1 and 2 referring to each part of the porosity. The hydraulic function is

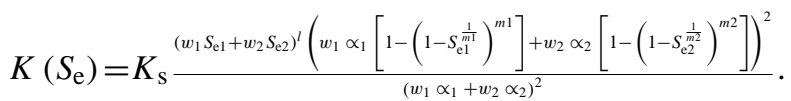

The goodness of the fit is analysed in this paper using the relative root mean square error (RRMSE) as Schaap and van Genuchten (2006), Weynants et al. (2009), Vereecken et al. (2010) - among others - did in a similar context. We compare models fitted on different amounts of observations considering retention data (Richards vs. $\mu \mathrm{CT}$ data). Besides, at least for $K(h)$ measurements, the measurement variability is greater near saturation. Finally, for the comparison between the models and the measurements for $K(h)$, we rely on three observed points (see Sect. 2.2.3).

RRMSE is calculated (following Alkasawneh et al., 2007) as

RRMSE $=\sqrt{\frac{1}{n} \sum_{i=1}^{n}\left(\frac{d_{i}-D_{i}}{D_{i}}\right)^{2}}$

with $n$ the number of measurements, $d_{i}$ the estimated value and $D_{i}$ the observed value. 
Table 1. RRMSE for fitting Richards' data set $(\mathrm{R})$ and combined data set $(\mu \mathrm{CT}+\mathrm{R})$ with van Genuchten (VG) or dual porosity (DP) model on retention functions.

\begin{tabular}{lccccc}
\hline Horizon & "R” VG & “R” DP & “ $\mu \mathrm{CT}+\mathrm{R}$ ” VG & “ $\mu \mathrm{CT}+\mathrm{R} ” \mathrm{DP}$ & “ $\mu \mathrm{CT}+\mathrm{R}$ ” DP* \\
\hline CT & 0.035 & 0.016 & 0.036 & 0.013 & 0.030 \\
RT1 & 0.039 & 0.044 & 0.048 & 0.012 & 0.021 \\
RT2 & 0.026 & 0.020 & 0.045 & 0.004 & 0.003 \\
\hline
\end{tabular}

* The last column is calculated using parameters from “ $\mu \mathrm{CT}+\mathrm{R}$ ” DP but on Richards' data alone.

\subsubsection{Hydraulic macroporosity efficiency}

Following Watson and Luxmoore (1986, cited by Imhoff et al., 2010), the number of hydraulically effective pores between two tensions is related to the difference between hydraulic conductivity for these two tensions $\left(K_{\mathrm{m}}, \mathrm{L} \mathrm{T}^{-1}\right)$ and can be calculated thanks to Poiseuille's law and the laminar flow equation:

$N_{m}=\frac{8 \eta K_{\mathrm{m}}}{\pi \rho g r_{\mathrm{a}}^{4}}$

where $\eta$ is the water dynamic viscosity $\left(\mathrm{ML}^{-1} \mathrm{~T}^{-1}\right)$ and $r_{\mathrm{a}}$ is the minimum pore radius (L). The associated macroporosity is equivalent to

$\theta_{\mathrm{m}}=N_{\mathrm{m}} \pi r_{\mathrm{a}}^{2}$.

The ratio between effective macroporosity and measured porosity is therefore an indicator of the hydraulic performances of the soil (Buczko et al., 2006 cited by Imhoff et al., 2010), and will be tested in our context.

\subsubsection{Principal component analysis}

Principal component analysis (PCA) has been widely described in the literature, for example in Benzécri and Benzécri (1980) cited by Palm (1994), or in Jackson (1991). PCA is a multivariate descriptive method. It aims at gathering descriptive parameters in a few components. The use of these components allows a 2-D representation of the data and highlights possible relationships between data and parameters. As Jackson (1980) said: "This method is used to simplify the simultaneous interpretation of a number of related variables."

PCA is performed here taking into account seven parameters (see Sect. 2.2.1): $\mathrm{Vol}, N_{\mathrm{c}}, \mathrm{Sf}_{\mathrm{c}}, \mathrm{SS}, R$, Def and SC.

\section{Results and discussion}

\subsection{Retention functions}

For the retention curves, the three horizons were analysed: CT, RT1 (0-10 cm depth) and RT2 (12-25 cm depth). Figure 4 represents both the data sets for each horizon. We used

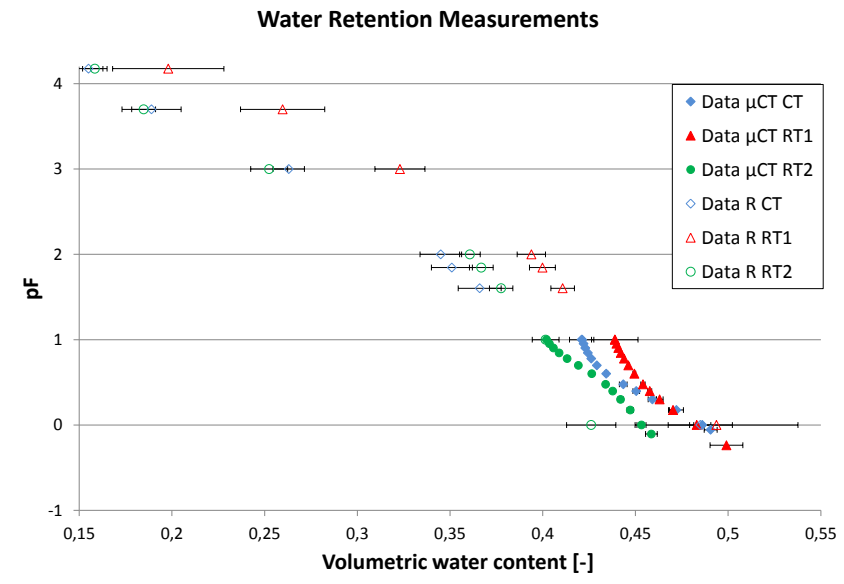

Figure 4. Water retention data for the three objects (CT, RT1, RT2) obtained with the Richards' procedure (empty dots) and with microtomography (full dots) for the entire tension range.

either the van Genuchten (1980) equation (VG) or the dual porosity (DP) model (Durner, 1994) to fit the data points. First, fitting is applied to Richards' measurements alone ("R"). In a second step, fitting is applied to a combination of Richards' (from $\mathrm{pF} 4.2$ to $\mathrm{pF} 1$ ) and $\mu \mathrm{CT}$ data (from $\mathrm{pF} 1$ to saturation) (called " $\mu \mathrm{CT}+\mathrm{R}$ ").

With the R fitting (see Fig. 5, dotted lines), RRMSEs are better with the DP model for CT and RT2 but not for RT1 (see Table 1), differences between VG and DP performances being quite important for CT.

Comparing the horizons with DP for $\mathrm{R}$, the only significant difference concerns the total effective porosity: it is significantly greater for CT than for RT2. RT1 is in between, but differences are not significant. We can see that near saturation, curves present different shapes. But the curves for RT are not well fitted for this part, especially for RT1.

The combination of Richards and $\mu \mathrm{CT}$ data is also fitted with the VG and DP models (see Fig. 5, solid lines). First, we can see that RRMSE (see Table 1) are widely better for the DP models than the VG ones. Indeed, the VG model can fit either Richards' data or $\mu \mathrm{CT}$ data, but fails in fitting a coupled data set. Supplementary pore systems have been integrated in retention function by Durner in 1994 and allow in many cases a better fitting of the retention data (see also Durner et al., 1999). In our study and except for RT1, 

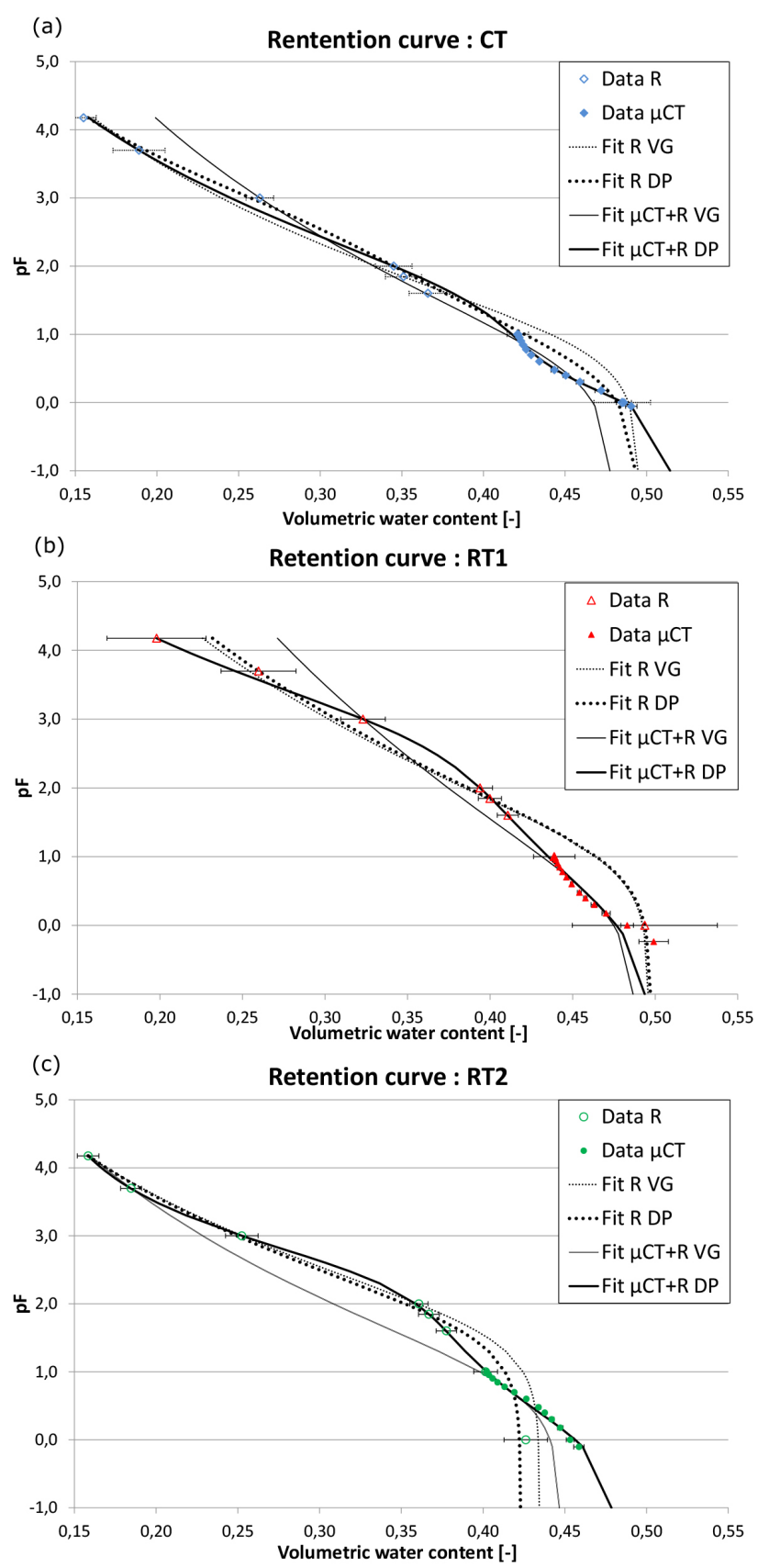

Figure 5. Retention curves. Dotted line: Richards' measurements (R); solid line: combined $\mu \mathrm{CT}$ and Richards' measurements $(\mu \mathrm{CT}+\mathrm{R})$; fine line: van Genuchten adjustment $(\mathrm{VG})$; thick line: dual porosity adjustment (DP).

taking into account this secondary pore system improves (in terms of RRMSE) the match between retention curves and retention measurements even if we consider Richards' measurements alone (see Table 1, columns 1 and 2). Besides, if we use the parameters set coming from the " $\mu \mathrm{CT}+\mathrm{R}$ " DP fit to calculate the RRMSE with Richards' measurements alone, the results are better than with VG (see Table 1, column 5).
These elements lead us to think that this secondary pore system is a characteristic of our soil and not an artefact coming from the collation of two data sets.

Looking at the combined DP curves, volumes from $\mathrm{pF} 1$ to saturation are not significantly different for the horizons. But we can see that for RT2, this volume is more important than with Richards' measurements $(p<0.05)$ while for CT and RT1 these volumes match. Considering this match and the elements of the image analysis pre-process (see Sect. 2.2.1), obviously Richards' procedure does not allow a good saturation estimation for RT2. The reason could be linked to the pore distribution.

We can also observe that the DP fit on R and both VG fits have much the same global shape around saturation, but not $\mathrm{CT}$ and $\mathrm{RT} 1 \mu \mathrm{CT}+\mathrm{R}$ DP curves. Indeed, comparing DP retention curves designed with $\mu \mathrm{CT}+\mathrm{R}$ and designed with $\mathrm{R}$, we observe that for CT and RT1, concavity is inverted from $\mathrm{pF} 1.2$ to saturation. With $\mu \mathrm{CT}$, the main part of the volume is closer to saturation than with $\mathrm{R}$ : For CT curve, the volume increase begins around $\mathrm{pF} 1$ and slows down around $\mathrm{pF} 0$ with $\mathrm{R}$, while with $\mu \mathrm{CT}$ the volume increase begins around $\mathrm{pF} 0.6$ and stops around $\mathrm{pF}-0.06$. As a result, $\mu \mathrm{CT}$ data show more pores with a bigger radius. These conclusions are the same for RT1 and RT2. For RT1, $\mu$ CT increase is even closer to saturation and consequently we have more and bigger pores than in CT. Furthermore for RT2, it is confirmed that fitting on $\mathrm{R}$ data leads to a bad approximation of porosity at saturation.

\subsection{Hydraulic conductivity}

\subsubsection{Hydraulic macroporosity efficiency}

If we compare macroporosity estimated from $K_{\text {sat }}$ measurements $\left(\theta_{\mathbf{M}}\right)$ vs. macroporosity estimated from Richards' and $\mu \mathrm{CT}$ measurements, we can use the ratio of these values as an indicator of macroporosity efficiency (ER) - in terms of conductivity ability - and pore network morphology. For both cases, we obtain the following trend: CT $>$ RT2 $>$ RT1 (see Table 2), with the latter being the most distant from Poiseuille's law with respect to structure morphology, i.e. reflecting poor dynamic performances. In fact, RT1 presents the higher near saturation pore volume while its saturated hydraulic conductivity is the lowest.

\subsubsection{Hydraulic functions}

Using $K_{\text {sat }}$ measured with the permeameter and results from fitted parameters with retention data, $K(h)$ curves with the four different adjustments are represented in Fig. 6 for each horizon. TI measurements are indicated as well, and the match between these points and fitting curves are calculated. For RT1 and RT2, the same TI measurements are used. But, because of the lower depth of RT1, measurements are likely to be attributed mostly to RT2. 
Table 2. $K_{\mathrm{S}}=$ saturated hydraulic conductivity $\left[\mathrm{m} \mathrm{s}^{-1}\right] ; N_{\mathrm{M}}=$ number of hydraulically effective pores; $\theta_{\mathrm{M}}=$ hydraulically effective macroporosity $\left[\mathrm{cm}^{3} \mathrm{~cm}^{-3}\right]$; ER = efficiency ratios for $\mu \mathrm{CT}(\mathrm{T})$ and Richards' $(\mathrm{R})$ measurements $(\mathrm{m})$.

\begin{tabular}{lclccc}
\hline Horizon & $K_{\mathrm{S}}\left(\mathrm{m} \mathrm{s}^{-1}\right)$ & $N_{\mathrm{M}}$ & $\theta_{\mathrm{M}}$ & ER T $(m)$ & ER R $(m)$ \\
\hline CT & $1.6 \times 10^{-4}$ & $8.1 \times 10^{-4}$ & $7.0 \times 10^{-1}$ & $1.2 \times 10^{-1}$ & $1.1 \times 10^{-1}$ \\
RT1 & $2.5 \times 10^{-5}$ & $1.3 \times 10^{4}$ & $1.1 \times 10^{-1}$ & $2.3 \times 10^{-2}$ & $2.0 \times 10^{-2}$ \\
RT2 & $4.0 \times 10^{-5}$ & $2.0 \times 10^{4}$ & $1.8 \times 10^{-1}$ & $3.8 \times 10^{-2}$ & $7.2 \times 10^{-2}$
\end{tabular}

Table 3. RRMSE for fitting Richards' data set (R) and combined data set $(\mu \mathrm{CT}+\mathrm{R})$ with van Genuchten $(\mathrm{VG})$ or dual porosity (DP) model on hydraulic functions.

\begin{tabular}{lrrcc}
\hline Horizon & "R" VG & “R” DP & “ $\mu \mathrm{CT}+\mathrm{R}$ ” VG & “ $\mu \mathrm{CT}+\mathrm{R}$ ” DP \\
\hline CT & 5.2 & 0.4 & 4.2 & 0.2 \\
RT1 & 1.9 & 0.3 & 0.9 & 1.0 \\
RT2 & 25.7 & 17.2 & 3.2 & 0.8 \\
\hline
\end{tabular}

Comparing fitted models, we can see that for CT the unsaturated flow prediction is particularly enhanced when taking into account the presence of a secondary pore system (see Table 3). For RT2, the best prediction is linked with the use of $\mu \mathrm{CT}$ complementary data. But in both cases, it is the combination of $\mu \mathrm{CT}$ data and the DP model that gives the best prediction of the unsaturated flow. These elements seem to validate the adjustment of elliptic cylinders to obtain pore size distribution.

Concerning RT1, results are much the same for " $\mu \mathrm{CT}+\mathrm{R}$ " data with VG and DP models, the better prediction being for R DP. The poor match for RT1 is probably caused by two factors. First, the TI measurements are probably more representative of RT2, and this is confirmed by the excellent match for this horizon. This assumption matches as well with our knowledge of the field and the measurements. Secondly, the DP retention curve on combined data does not fit very well between $\mathrm{pF} 0$ and saturation. RT1 measurements present a great variability especially in this pressure range; therefore the mean curve might not be representative of the mean behaviour. Actually, Durner et al. (1999) mention the possible difficulty of averaging dual porosity curves in some cases.

We can see that both fittings on $\mathrm{R}$ and $\mu \mathrm{CT}+\mathrm{R}$ with the DP model allow a better adjustment for retention curves. Our results show that for $\mathrm{R}$ retention curves DP improves the fitting, but not significantly. Actually, without complementary information, it is difficult to choose a model. It is generally accepted that unimodal models - like VG - are adequate and, because of their easier implementation, are therefore often preferred (Durner et al., 1999). But in our case, the DP model proves to better predict the unsaturated conductivity. This is supported by the results of Durner et al. (1999) on silty soils. They show that the more parameters that are involved, the better the fitting on hydraulic functions, i.e. multimodal models. The fact that microtomography demonstrates this, as well as allowing a better prediction of the unsaturated hydraulic conductivity, are evidence for the validation of microtomographic information.

Further, $\mu \mathrm{CT}$ data allow refining retention and hydraulic curves near saturation where Richards' data alone can lead to numerous sets of fitted parameters. However, other methods allow this as well (for example, Hyprop apparatus, UMS ${ }^{\circledR}$ ). But microtomographic images processed with an appropriate algorithm may be more powerful. Matching micro and macroscopic measurements allows us to validate $\mu \mathrm{CT}$ information, which is otherwise not so obvious (Baveye et al., 2010). The algorithm we use (Plougonven, 2009; Plougonven and Bernard, 2011) proves to be effective at separating pores individually since both retention and conductivity functions present an enhancement: pore size distribution obtained with this method and the fit of an elliptic cylinder on pores converge to obtain good results. An efficient pore individualization is interesting in soil analyses. Indeed, reproducing accurately the soil behaviour is still a challenge. Notably, characteristics, when calculated on the entire pore space, are influenced by little but numerous pores and are not able to reproduce global behaviour. On the other hand, precise individual characterization could be used to improve our knowledge of the pore space and its modelling. The next step is therefore to make use of potential structural information on individual pores.

\subsection{X-ray microtomography: principal component analysis}

PCA is performed on our samples, taking into account seven parameters (see Sect. 2.2.1): Vol, $N_{\mathrm{c}}, \mathrm{Sf}_{\mathrm{c}}, \mathrm{SS}, R$, Def and SC. The first three components explain about $90 \%$ of the variability between samples; F1 (the first component) alone explains $54 \%$ of the variability. All seven parameters are well correlated at least for one component. We represent in Fig. 7 (a 2-D representation of PCA with the two first components, F1-F2) and Fig. 8 (a 2-D representation of PCA with the first (F1) and third (F3) components) the results for pores with a radius $>1500 \mu \mathrm{m}(h>-1 \mathrm{mbar})$, because of their bigger influence on hydrodynamic behaviour. CT and RT2 are in opposition with RT1 along F1. RT1 and RT2 differ because of a lower surface of connections and a bigger specific surface for RT2, while RT1 and CT are disconnected because of larger volume and radius, and a lower specific surface for 

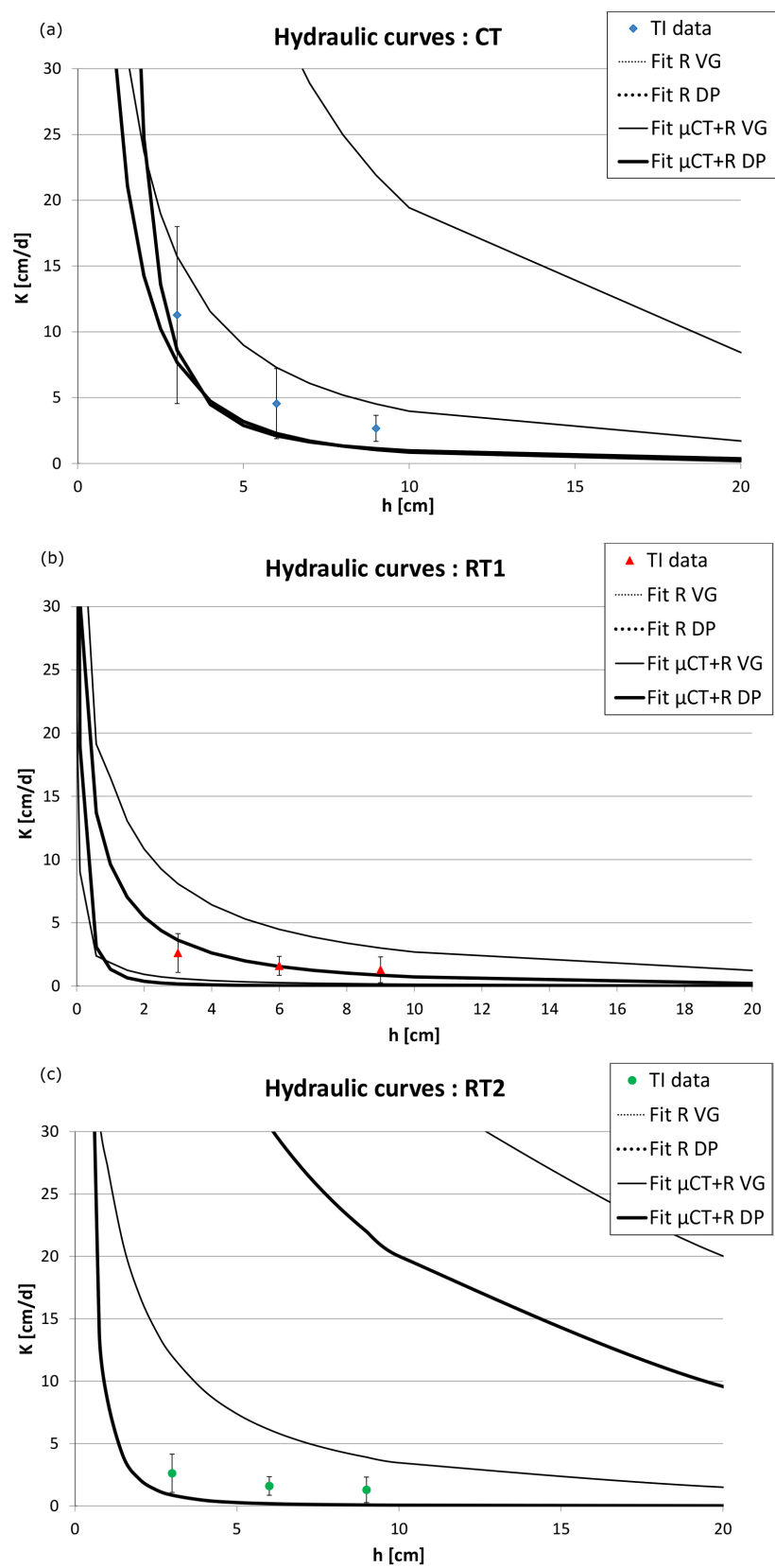

Figure 6. Hydraulic curves. Dotted line: Richards' measurements (R); solid line: combined $\mu \mathrm{CT}$ and Richards' measurements $(\mu \mathrm{CT}+\mathrm{R})$.

RT1. While this representation of the objects does not underline great differences between them (full dots, Fig. 7), we can still observe along F1 the ranking $\mathrm{CT}<\mathrm{RT} 2<\mathrm{RT} 1$, which is the reverse order as compared to macroporosity conductivity efficiency. Vogel and Roth (1998) demonstrate that realistic pore network representation has to take into account its connectivity and tortuosity. Our PCA is consistent with their results since specific surface and specific connectivity are highly correlated with F1. The importance of these structural

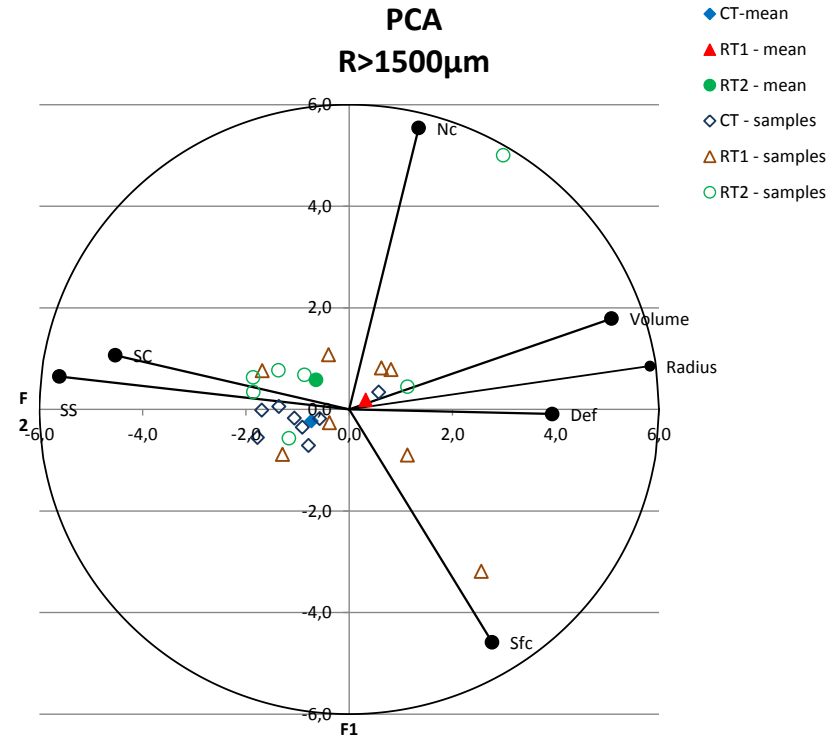

Figure 7. PCA scores for pores with $r>1500 \mu \mathrm{m}$ with the first F1, $54 \%$ ) and second (F2, $23 \%$ ) components.

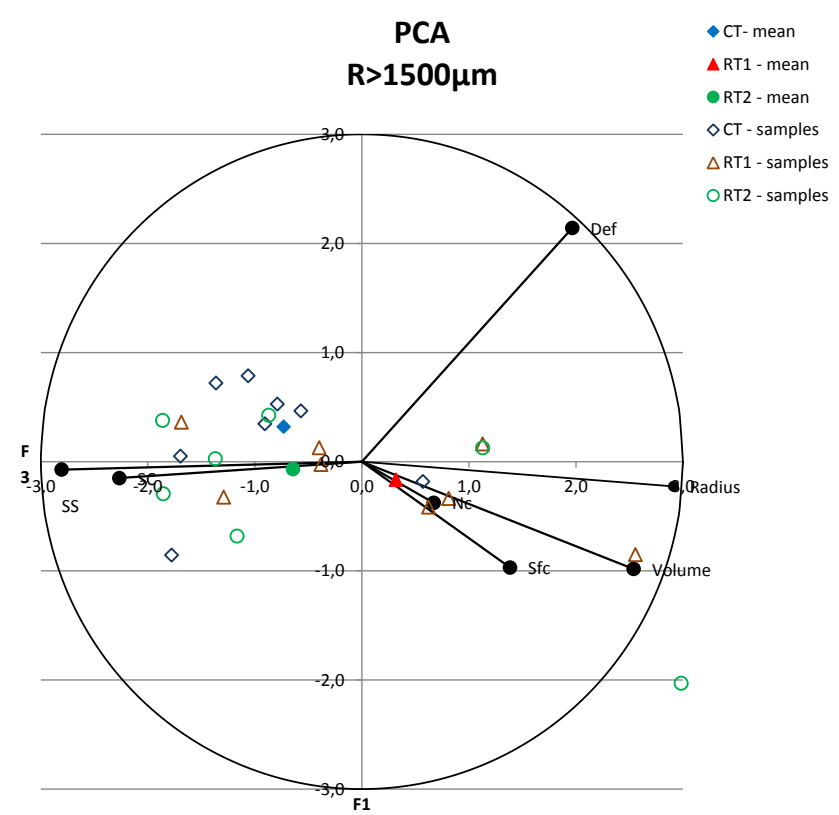

Figure 8. PCA scores for pores with $r>1500 \mu \mathrm{m}$ with the first (F1, $54 \%)$ and third (F3, $11 \%)$ components.

parameters in our object differentiation strengthens the idea that macroporosity is not the only parameter to consider for conductivity characterization.

In addition to the conclusions about the mean structural parameters, the position of the samples in PCA representation can be seen as object intra-variability and provides supplementary clues. That is to say, the dispersion coefficient is very low for CT. It is important for RT2, but because of one sample alone, while RT1 is characterized by a 
dispersed spatial position of the samples (see Table 4). This behaviour seems to be symptomatic for this horizon. If we analyse macroscopic measurements from this point of view (not presented here), we can see that the horizons present the same characteristics as above about variability. CT has a low variation range and its mean and median are often superimposed. RT2 also has a low variation range, but its mean is displaced because of a few outliers. And finally RT1 presents a higher variation range and big differences between mean and median.

We could conclude that the poor dynamic performances reflected by ratio between macroporosity and saturated hydraulic conductivity - for RT1 can be linked to this great heterogeneity (and therefore agrees with the divergence found in the literature, e.g. Strudley et al., 2008), while for RT2 it is more related to a generally low permeable medium. However, outliers seem to be a rule in RT2 populations, one of the main reasons probably being a greater pedofaunistic activity - which is in accord with results of Cousin et al. (2004). Indeed, pedofaunae produce large pores which can be observed with $\mu \mathrm{CT}$ and permeability measurements - but occur rarely - because of the size of the samples; while Richards' measurements are not able to detect them because of the difficulty to completely saturate the largest macropores.

\section{Conclusions}

The central point of this paper is to show that X-ray microtomography brings supplementary and complementary information to macroscopic measurements in the context of agricultural practice evolution. It is a bridge between micro- and macroscopic approaches. More precisely, our research shows that: (i) we have an agreement between measurements at the macroscopic and the microscopic scales (ii) behaviours at these different scales can be linked together (iii) microscopic information can enhance macroscopic description and modelling.

In this work, we validate our methodology chain with a relatively quick scan method. Microtomography is still restricted by the numerous steps and choices of image processing. Nevertheless, the good match for both retention and conductivity functions with macroscopic measurements validates globally the $\mu \mathrm{CT}$ information, since the macroscopic measurements match the pore volume distribution through the adjustment of an elliptic cylinder. As a result, we show that a mean macroscopic behaviour can be linked with a mean behaviour at the microscopic scale. Indeed, while most research deals with pore network modelling, we show that X-ray microtomography can be used to enhance plot scale models. More specifically, the pore size distribution derived from microtomography allows us to enhance the near-saturation hydraulic function through parameterization of a double porosity model. Furthermore, we have put in evidence microtomographic parameters which could contribute
Table 4. Dispersion coefficient of the samples in the PCA 3-D space for all the samples ("All") and for all the samples except the farthest from the mean ("All - 1").

\begin{tabular}{lcc}
\hline Horizon & "All” & "All $-1 "$ \\
\hline CT & 0.6 & 0.2 \\
RT1 & 3.5 & 1.6 \\
RT2 & 4.9 & 1.2 \\
\hline
\end{tabular}

to explain the mean hydrodynamic behaviour of these soils. Analysis of structural parameters for the biggest pores appears to be significant and offers an additional step in object differentiation. PCA shows that seven structural parameters can explain nearly $90 \%$ of the variability between horizons, and that it is important to differentiate them. The most determining parameters in our context are specific surface, specific connectivity, volume and radius. The next step is the improvement of hydraulic functions via X-ray microtomography structural parameters, for example by including a connectivity and/or a specific surface-based parameter in the function implementation.

Note that with X-ray tomography, the acquired images can constitute a growing database, and that new algorithms can be applied and tested repeatedly. Indeed, images are not damaged by the calculations and more information can thus be obtained as computer resources increase or as algorithms are developed.

Acknowledgements. The authors would like to thank the referees of the paper for their helpful advice. The authors would also like to thank Sébastien Jacqmin for his great work on the illustration of the pore network.

Edited by: A. Shamseldin

\section{References}

Alkasawneh, W., Pan, E., and Green, R.: Effect of the Relative RootMean-Square error on Pavement Response, Anal. Asphalt Pave. Mater. Syst., 176, 117-132, doi:10.1061/40924(308)10, 2007.

Attix, F. H. R. and Roesch, W. C.: Radiation dosimetry, Academic Press, New York, 1968.

Baveye, P. C., Laba, M., Otten, W., Bouckaert, L., Dello Sterpaio, P., Goswami, R. R., Grinev, D., Houston, A., Hu, Y., Liu, J., Mooney, S., Pajor, R., Sleutel, S., Tarquis, A., Wang, W., Wei, Q., and Sezgin, M.: Observer-dependent variability of the thresholding step in the quantitative analysis of soil images and X-ray microtomography data, Geoderma, 157, 51-63, 2010.

Bayer, A., Vogel, H.-J., and Roth, K.: Direct measurement of the soil water retention curve using X-ray absorption, Hydrol. Earth Syst. Sci., 8, 2-7, doi:10.5194/hess-8-2-2004, 2004. 
Beckers, E., Plougonven, E., Roisin, C., Hapca, S., Léonard, A., and Degré, A.: X-ray microtomography: A porosity-based thresholding method to improve soil pore network characterization?, Geoderma, 219-220, 145-154, 2014.

Bhattacharyya, R., Prakash, V., Kundu, S., and Gupta, H. S.: Effect of tillage and crop rotations on pore size distribution and soil hydraulic conductivity in sandy clay loam soil of the Indian Himalayas, Soil Till. Res., 86, 129-140, 2006.

Cousin, I., Vogel, H.-J., and Nicoullaud, B.: Influence de la structure du sol à différentes échelles sur les transferts d'eau : Conséquences d'une réduction du travail du sol, Étude Gestion Sols, 11, 69-81, 2004.

Dal Ferro, N., Delmas, P., Duwig, C., Simonetti, G., and Morari, F.: Coupling X-ray microtomography and mercury intrusion porosimetry to quantify aggregate structures of a cambisol under different fertilisation treatments, Soil Till. Res., 119, 13-21, 2012.

DIN ISO 11274: Soil quality - Determination of the water retention characteristics - Laboratory methods (ISO 11274:1998 + Cor. 1:2009) English translation of DIN ISO 11274:2012-04, Deutsches Institut für Normung, Berlin, Germany, 2012.

Durner, W.: Hydraulic conductivity estimation for soils with heterogeneous pore structure, Water Resour. Res., 30, 211-233, 1994.

Durner, W., Priesack, E., Vogel, H. J., and Zurmühl, T.: Determination of parameters for flexible hydraulic functions by inverse modeling, in: Workshop, Characterization and Measurement of the Hydraulic Properties of Unsaturated Porous Media Proc. Int. , edited by: van Genuchten, M. Th., Leij, F. J., and Wu., L., University of California, Riverside, CA, 817-830, 1999.

Eden, M., Moldrup, P., Schjonning, P., Vogel, H. J., Scow, K. M., and de Jonge, L. W.: Linking soil physical parameters along a density gradient in a loess soil long-term experiment, Soil Sci., 177, 1-11, 2012.

Gerke, H. H.: Macroscopic representation on of the interface between flow domains in structured Soil, Vadose Zone J., 11, doi:10.2136/vzj2011.0125, 2012.

Green, T. R., Ahujaa, L. R., and Benjamin, J. G.: Advances and challenges in predicting agricultural management effects on soil hydraulic properties, Geoderma, 116, 3-27, 2003.

Hapca, S. M., Houston, A. N., Otten, W., and Baveye, P. C.: New objective segmentation method based on minimizing locally the intra-class variance of grayscale images, Vadose Zone J., 12, doi:10.2136/vzj2012.0172, 2013.

Holthusen, D., Jänicke, M., Peth, S., and Horn, R.: Physical properties of a Luvisol for different long-term fertilization treatments: I. Mesoscale capacity and intensity parameters, J. Plant Nutr. Soil Sc., 175, 4-13, 2012.

Houston, A. N., Otten, W., Baveye, P. C., and Hapca S.: Adaptivewindow indicator kriging: A thresholding method for computed tomography images of porous media, Comput. Geosci., 54, 239248,2013

Iassonov, P., Gebrenegus, T., and Tuller, M.: Segmentation of X-ray computed tomography images of porous materials: a crucial step for characterization and quantitative analysis of pore structures, Water Resour. Res., 45, W09415, doi:10.1029/2009WR008087, 2009.
Imhoff, S., Ghiberto, P. J., Grioni, A., and Gay, J. P.: Porosity characterization of Argiudolls under different management systems in the Argentine Flat Pampa, Geoderma, 158, 268-274, 2010.

Jackson, J. E.: Principal components and factor analysis: Part IPrincipal components, J. Qual. Technol., 12, 201-213, 1980.

Jackson, J. E.: A user's guide to principal components, Wiley, New York, 1991.

Kim, H., Anderson, S. H., Motavalli, P. P., and Gantzer, C. J.: Compaction effects on soil macropore geometry and related parameters for an arable field, Geoderma, 160, 244-251, 2010.

Kumar, S., Anderson, S. H., and Udawatta, R. P.: Agroforestry and grass buffer influences on macropores measured by computed tomography under grazed pasture systems, Soil Sci. Soc. Am. J., 74, 203-212, 2010.

Levenberg, K.: A Method for the Solution of Certain Problems in Least Squares, Quart. Appl. Math., 2, 164-168, 1944.

Marquardt D.: An Algorithm for Least-Squares Estimation of Nonlinear Parameters, SIAM J. Appl. Math., 11, 431-441, 1963.

Mualem, Y.: A new model for predicting the hydraulic conductivity of unsaturated porous media, Water Resour. Res., 12, 513-522, 1976.

Olsen, P. A. and Borresen, T.: Measuring differences in soil properties in soils with different cultivation practices using computer tomography, Soil Till. Res., 44, 1-12, 1997.

Palm, R.: Les méthodes d'analyse factorielle: principes et applications, Biom. Praxim., 34, 35-80, 1994.

Plougonven, E.: Link between the microstructure of porous materials and their permeability, Ph.D. Thesis, Université Bordeaux 1, Bordeaux, 2009.

Plougonven, E. and Bernard, D.: Optimal removal of topological artefacts in microtomographic images of porous materials, Adv. Water Resour., 34, 731-736, 2011.

Quinton, W. L., Elliot, T., Price, J. S., Rezanezhad, F., and Heck, R.: Measuring physical and hydraulic properties of peat from X-ray tomography, Geoderma, 153, 269-277, 2009.

Rachman, A., Anderson, S. H., and Gantzer, C. J.: Computed tomographic measurement of soil macroporosity parameters as affected by stiff-stemmed grass hedges, Soil Sci. Soc. Am. J., 69, 1609-1616, 2005.

Richards, L. A.: Porous plate apparatus for measuring moisture retention and transmission by soils, Soil Sci., 66, 105-110, 1948.

Roisin, C.: A multifractal approach for assessing the structural state of tilled soils, Soil Sci. Soc. Am. J., 71, 15-25, 2007.

Schaap, M. G. and van Genuchten, M. Th.: A Modified Mualemvan Genuchten Formulation for Improved Description of the Hydraulic Conductivity Near Saturation, Vadose Zone J., 5, 27-34, doi:10.2136/vzj2005.0005, 2006.

Schlüter, S., Weller, U., and Vogel, H.-J.: Segmentation of X-ray microtomography images of soil using gradient masks, Comput Geosci., 36, 1246-1251, 2010.

Schlüter, S., Weller, U., and Vogel, H.-J.: Soil-structure development including seasonal dynamics in a long-term fertilization experiment, J. Plant Nutr. Soil Sc., 174, 395-403, 2011.

Solone, R., Bittelli, M., Tomei, F., and Morari, F.: Errors in water retention curves determined with pressure plates: Effects on the soil water balance, J. Hydrol., 470-471, 65-74, 2012.

Strudley, M. W., Green, T. R., and Ascough, J. C.: Tillage effects on soil hydraulic properties in space and time: State of the science, Soil Till. Res., 99, 4-48, 2008. 
Taina, I. A., Heck, R. J., and Elliot, T. R.: Application of X-ray computed tomography to soil science: A literature review, Can. J. Soil Sci., 88, 1-20, 2008.

van Genuchten, M. Th.: A closed-form equation for predicting the hydraulic conductivity of unsaturated soils, Soil Sci. Soc. Am. J., 44, 892-898, 1980.

Vereecken, H., Weynants, M., Javaux, M., Pachepsky, Y., Schaap, M. G., and van Genuchten, M. Th.: Using Pedotransfer Functions to Estimate the van Genuchten-Mualem Soil Hydraulic Properties: A Review, Vadose Zone J., 9, 795-820, doi:10.2136/vzj2010.0045, 2010.

Vogel, H. J. and Roth, K.: A new approach for determining effective soil hydraulic functions, Eur. J. Soil Sci., 49, 547-556, 1998.
Wang, W., Kravchenko, A. N., Smucker, A. J. M., and Rivers, M. L.: Comparison of image segmentation methods in simulated 2D and 3D microtomographic images of soil aggregates, Geoderma, 162, 231-241, 2011.

Weynants, M., Vereecken, H., and Javaux, M.: Revisiting Vereecken pedotransfer functions: Introducing a Closed-Form Hydraulic Model, Vadose Zone J., 8, 86-95, doi:10.2136/vzj2008.0062, 2009.

Wiermann, C., Werner, D., Horn, R., Rostek, J., and Werner, B.: Stress/strain processes in a structured unsaturated silty loam Luvisol under different tillage treatments in Germany, Soil Till Res., 53, 117-128, 2000. 